\title{
ESTUDO DA CODEPENDÊNCIA NAS MULHERES DE USUÁRIOS DE SUBSTÂNCIAS PSICOATIVAS ILIICITAS
}

Josinéia dos Santos de Lemos Vasconcellos ${ }^{1}$ Laíssa Eschiletti Prati ${ }^{2}$

\begin{abstract}
RESUMO
Codependência é um constructo que pretende explicar a relação de dependência que a pessoa desenvolve pela convivência com dependentes (de substâncias psicoativas ou outras situações). Este estudo analisou a codependência em 30 mulheres de usuários de substâncias psicoativas ilícitas. Utilizando o Instrumento de Codependência (ICOD; GAYOL; LIRA, 2002), buscou-se verificar correlações entre codependência, a idade das mulheres, o tipo de droga utilizado, o tempo de uso de substâncias ilícitas pelos maridos e o tempo dedicado para atender às necessidades dos parceiros, configurando uma pesquisa quantitativa correlacional. Os resultados apontaram a presença de codependência em $90 \%$ das mulheres, além do fato de que o grupo das mulheres cujo marido/companheiro já fez tratamento apresenta um índice maior de codependência. Outros estudos sobre a codependência na realidade brasileira devem ser conduzidos, incluindo a elaboração ou validação de instrumentos que identifiquem e mensurem a codependência em mulheres e, sobretudo, em familiares de origem do dependente químico.
\end{abstract}

Palavras-chave: Codependência. Drogas. Relações conjugais.

\section{ABSTRACT}

Codependency is a construct that intent to explain the dependency relation developed by the person that cohabit with dependents (psychoactive substances or others situations). This study analyzed the codependency in 30 spouses which husbands are illicit psychoactive substances user. Using the Codependency Instrument (IOCD; GAYOL; LIRA, 2002), correlations between codependency, women age, kind of drugs used, duration of the use of drugs in life span by husbands and time available for deal with partner needs were studied, configuring a quantitative correlational research. Results indicated the presence of Codependency in 90\% of the participants and that the group in with partner already star-

\footnotetext{
${ }^{1}$ Psicóloga formada pelo Curso de Psicologia das Faculdades Integradas de Taquara (Faccat)/RS.

josineia.vasconcellos@gmail.com

2 Doutora em Psicologia. Professora do curso de Psicologia da Faccat/RS. laissa@faccat.br
} 
ted a treatment shows a higher level of codependency. Others studies about codependency must be conducted, including validation or creation of instruments that identify and measure codependency in women, specially, women from dependent origin family.

Keywords: Codependency. Drugs. Conjugal relations.

\section{INTRODUÇÃO}

Com o aumento do consumo de drogas ilícitas, torna-se de fundamental importância o aprofundamento dos estudos sobre dependência química e demais questões que circundam esse tema. A codependência é uma das áreas que vem sendo explorada detalhadamente em famílias de usuários de drogas lícitas. Ela está presente nas relações familiares disfuncionais em que uma pessoa desempenha o papel de "cuidador" do dependente, enquanto o outro membro do sistema familiar desempenha papel de dependente de algo. Este estudo explora essa relação no caso de dependência de drogas ilícitas.

Ao longo dos anos, o termo codependência tem sido aprimorado. Compreende-se que a pessoa codependente vincula-se a sistemas disfuncionais e desenvolve um padrão disfuncional de lidar com os problemas, desenvolver e manter relações afetivas (LARSE apud BEATTIE, 1992; SUBBY, 1987; BLACK, 1982 apud ORTIZ, 2009). O codependente torna-se refém de tudo o que envolve o outro (HEMFELT; MINIRTH; MEIER, 1989 apud BRASIL, 2004).

O acompanhamento de famílias que buscam tratamento em uma Comunidade Terapêutica do Sul do Brasil indica que tanto o usuário quanto a família estão adoecidos, necessitando tratamento. Embora existam famílias que afirmam a necessidade de tratamento somente para o usuário, outras reconhecem que, além do usuário receber tratamento, elas também precisam de acompanhamento para aprender a lidar com o problema das drogas.

A observação informal de profissionais que trabalham com familiares de dependentes químicos em diversas instituições de saúde indicam que o estudo da codependência é relevante para o tratamento do paciente. A partir da abordagem sistêmica, eles dão ênfase à intervenção que deve ser realizada no sistema familiar, já que a problemática das drogas se dá, em grande parte, em um ambiente disfuncional. É importante "desintoxicar" a família dos hábitos nocivos que favorecem o uso de drogas (SCHNEIDER et al., 2004).

Considerando fundamentais os estudos sobre a codependência em mulheres de usuários de substâncias psicoativas ilícitas, este estudo analisou a presença ou não de codependência nesse público. Verificou se a idade das mulheres, o tempo dedicado para atender às necessidades do parceiro, o tipo de droga ilícita utilizada pelo cônjuge e o tempo que o parceiro consome a substância correlacionam-se com a codependência da mulher. O objetivo deste estudo é fornecer material para o melhor entendimento da codependência na realidade Brasileira (que é carente destes estudos). Além disso, a partir do conhecimento dessas relações, melhores estratégias para auxiliar no tratamento do dependente químico e da sua família poderão ser desenvolvidas. 


\section{DROGADIÇÃO E FAMÍLIA}

Atualmente, o uso de drogas tem contribuído para o aumento de problemas de ordem biopsicossocial. Na saúde física, percebe-se perda de apetite, insônia, queda de pressão, perda de tecido cerebral, ânsia de vômito, mortes prematuras (IBGE, 2009), arritmia cardíaca, trombose, AVC, necrose cerebral, insuficiência renal e cardíaca, disfunções no sistema reprodutor e respiratório, câncer, espinhas, convulsões, desidratação e exaustão (CABRAL, 2009), gravidez indesejada, infarto do miocárdio e doenças sexualmente transmissíveis (REBOUSSIN et al., 2006 apud VIEIRA, 2007) dentre outros. Já na área da saúde mental, destacam-se danos à inteligência, depressão (IBGE, 2009), disforia, alterações nas funções motoras, perda de memória (CABRAL, 2009), transtornos de ansiedade (NARDI, 2009), alexitimia (VASCONCELLOS; PERGHER, 2008), etc. No âmbito social, é possível observar os prejuízos nas relações interpessoais como o avanço da violência urbana, acidentes de trânsito (ANDRADE, 2008), gastos com tratamento médico e internações, comportamento sexual de risco (PILLON; O'BRIEN; CHAVEZ, 2005), criminalidade (SOARES; REZENDE, 2007), tráfico de drogas (BATISTA, 1996 apud DIMENSTEIN; ZAMORA; VILHENA, 2004), miséria (FERRUZZI et al., 2004), como também o prejuízo nas relações familiares (ANDRADE, 2008).

Ao longo do tempo, a estrutura familiar tem sofrido modificações provindas do meio externo. Antes do século XX, era mantida uma relação de hierarquia, sendo o homem o provedor do sustento e o que exercia o poder marital sobre a mulher e o pátrio poder sobre os filhos (LÔBO, 2004). A mulher exercia uma posição de submissão, permanecendo a serviço do seu senhor, e a ela cabia a responsabilidade doméstica. Devido à relação de hierarquia, o distanciamento entre pais e filhos era comum e, para manter o respeito, a manifestação de afeto era mínima e distante. Essa manifestação ocorria somente em situações formais. Diante de assuntos importantes, somente os pais discutiam e buscavam estratégias de resolução, restando aos filhos o dever de apenas obedecer às ordens dos adultos, sem ter, inclusive, qualquer direito de serem informados sobre $o$ assunto (HINTZ, 2001).

Por meio da legislação brasileira de 1943, foi dada à mulher casada a liberdade de trabalhar, não necessitando do consentimento do marido. Contudo, essa liberdade era restrita às mulheres e aos filhos que não estavam recebendo o suprimento das necessidades básicas por intermédio do seu provedor. A partir das duas guerras mundiais, a relação de hierarquia foi transformada em relação de igualdade, e o ser humano passou a ser visto como indivíduo dotado de valores e capacidades. Por meio da pílula anticoncepcional, implantada na década de 60 , a mulher pôde controlar a procriação de filhos, como também participar junto com o marido de tomadas de decisões, não somente acerca da educação dos filhos, também sobre as atividades administrativas e financeiras da família (BUCHER, 1999 apud HINTZ, 2001; MELER apud HINTZ, 2001; VAITSMAN, 1994). A relação parental também sofreu modificações. A manifestação de afeto começou ser mais explícita, além da possibilidade de manter conversação entre pais e filhos (HINTZ, 2001).

Na metade do século XX, o número de membros que compunham a família se reduziu a pai, mãe e filhos, passando a denominar-se nuclear. Os pais assumiram definitivamente a responsabilidade pela educação dos filhos, diminuindo, assim, a rede de 
apoio da família extensa. Os membros desse novo núcleo mantinham uma relação afetiva e não mais de dependência da família de origem, eles passaram a habitar em espaço físico diferente (HINTZ, 2001).

Assim como a família sofreu modificações internas, fatores externos contribuíram para alterar a estrutura familiar de maneira positiva e negativa. Diante da necessidade econômica, a mulher passou a realizar atividades externas para aumentar a renda familiar. Com o passar do tempo, sua responsabilidade doméstica e a educação dos filhos foi transferida para terceiros, resultando em fonte de conflitos. O avanço tecnológico é outro fator que modificou a relação conjugal e parental. O que poderia possibilitar uma melhor qualidade de vida resultou em dificuldades, distanciamentos e até separação entre as pessoas do núcleo familiar. Com o distanciamento dos cônjuges e a tentativa de atender às demandas atuais da sociedade, surgem novas configurações familiares, entre elas, as famílias monoparentais. Normalmente, essa estrutura familiar é composta por mãe e filhos (HINTZ, 2001; SORJ; FONTES; MACHADO, 2007). Outro fator que compromete a estabilidade da família é a dependência química e os problemas que estão associados a ela, entre eles a codependência (SECRETARIA DE SALUD, 1988 apud GAYOL; LIRA, 2002).

A origem do termo codependência surgiu na década de 1930, em algumas instituições de saúde mental nos Estados Unidos. As mulheres dos usuários de álcool eram entrevistadas por assistentes sociais. Durante as entrevistas, as profissionais observavam que as mulheres se mostravam altamente preocupadas, vinculadas com os esposos, além de estarem ansiosas, angustiadas e com grau elevado de depressão. Naquela época, já era oferecida uma proposta de ajuda para os dependentes de álcool. Contudo, foi na década de 40 que o termo codependência começou a ser estruturado, passando a ser o foco do estudo as esposas dos usuários de álcool (SILVA, 2009).

Na década de 50, mulheres de dependentes de álcool que estavam em recuperação decidiram montar um grupo de partilha, uma vez que percebiam que elas também haviam sido afetadas em seus aspectos físicos, emocionais, psicológicos e espirituais. Acreditavam que necessitavam da mesma atenção ou tratamento oferecido para os seus esposos para a superação da codependência (ORTIZ, 2009). Elas se reuniam a fim de discutir suas experiências com os esposos alcoólatras e para debater as situações estressantes que enfrentavam. Em grupo, elas elaboravam estratégias de enfrentamento para o problema (SILVA, 2009). Foi realizado um estudo com mulheres que frequentavam o grupo de autoajuda Al-Anon, e as mulheres admitiram que estavam tão enfermas quanto os seus esposos que usavam álcool (ABLON, 1974 apud ORTIZ, 2009). As famílias dos alcoólatras eram conhecidas pelo termo coalcoólicos. O termo referia-se à capacidade não desenvolvida de reconhecer e expressar afeto por si mesma, passando a responsabilizar-se pelos outros. O coalcoólico tentava controlar e manipular as pessoas, os lugares e as coisas, buscando dar um sentido à sua vida a partir desse movimento (ORTIZ, 2009).

A partir do final da década de 70, Black (1982 apud ORTIZ, 2009) ampliou o conceito de coalcoolismo para codependência, enfatizando as consequências para um indivíduo nas áreas emocionais, psicológicas e comportamentais a partir de um sistema familiar disfuncional. Pessoas desenvolvem um padrão disfuncional ao lidar com os problemas, utilizando estratégias como projeção, minimização, intelectualização e negação, para a manutenção do problema (SUBBY, 1987). Esses comportamentos disfuncionais 
dificultam a iniciação ou participação nas relações afetivas mais saudáveis (LARSE apud BEATTIE, 1992). Na tentativa de controlar os próprios sentimentos, o codependente torna-se refém de tudo que envolve o outro: sentimentos, droga, trabalho, problemas, comida, responsabilidades entre outros (HEMFELT; MINIRTH; MEIER, 1989 apud BRASIL, 2004). A pessoa codependente passa a viver a intimidade do outro, restringindo o seu próprio EU e lutando incansavelmente para preencher o vazio emocional que há no seu próprio interior. Silva (2000) destaca que o codependente sente-se atraído por aquilo que é disfuncional. Assim, algumas regras básicas podem favorecer o desenvolvimento de um codependente no meio familiar. São apresentados como exemplos: evitar falar dos problemas, a comunicação ser triangular e não direta, não permitir um espaço para externar os sentimentos, incongruência entre a fala e a execução de um comportamento. Essas regras não auxiliam no desenvolvimento da autoestima e no enfrentamento de problemas (ALL ABOUT COUNSELING, 1998).

A codependência no abuso de drogas está relacionada a uma interação familiar disfuncional, em que o esposo assume o papel do dependente da substância, a esposa desempenha papel de "mártir", e os filhos desempenham o papel de negligenciados (FERREIRA, 2008). A psicologia sistêmica, a partir do grupo de Milão, considera o dependente químico como o "paciente identificado". Os membros da família exigem, de uma maneira implícita, que esse paciente mude sem alterar a estrutura familiar. $\mathrm{O}$ paciente torna-se refém deste meio, em que a família resiste às propostas necessárias de mudanças (ZAMPIERI, 2004). Conforme a doença vai se instalando no indivíduo, as consequências começam a aparecer. O codependente passa a organizar a sua vida em torno do dependente químico, resultando em sérios prejuízos nas áreas biopsicossociais. Na área biológica, estudos têm relacionado a codependência ao desenvolvimento do câncer (GAFAS, 2009) e a doenças físicas relacionadas ao estresse crônico (ALL ABOUT COUNSELING, 1998). Na área psicológica, é possível encontrar depressão, baixa autoestima, intenso sentimento de culpa, desconfiança (GAFAS, 2009), sentimento de vazio, perfeccionismo, hipervigilância (ALL ABOUT COUNSELING, 1998), senso de vitimização, atração por pessoas explosivas, controle compulsivo, preocupação excessiva com o outro e visão de futuro limitada (ZAMPIERI, 2004). Já na área social, o codependente mantém atitudes de autoanulação, suicídio, assassinato (GAFAS, 2009) e isolamento (BRASIL, 2004).

É possível constatar que a codependência vai além de famílias de usuários de substâncias psicoativas. Em 1987, profissionais perceberam que a codependência não acontecia somente nas famílias de dependentes químicos, mas em qualquer sistema familiar que possuía regras implícitas ou explícitas que interferissem no desenvolvimento emocional, psicológico, comportamental e espiritual (SUBBY, 1987). Foram identificados alguns papéis rígidos e inflexíveis vivenciados durante a infância que favorecem o surgimento de um comportamento codependente. O primeiro papel explicitado é o de bode expiatório: quando os filhos estão sempre recebendo correções por apresentar comportamentos inadequados, embora o interesse seja de chamar a atenção dos pais. O papel de herói: quando o filho, em tenra idade, assume as responsabilidades que os pais não assumem e "carrega a casa sozinho". O papel de mascote: a criança procura deslocar os problemas do sistema familiar, chamando a atenção dos demais membros da família, através de piadas, brincadeiras e risos, porém, por trás do sorriso, há um grande sofri- 
mento. O papel de facilitador: busca minimizar e apaziguar as situações, proporcionando um ambiente de proteção para o dependente, assumindo suas responsabilidades e resolvendo seus problemas, além de culpabilizar-se e excluir-se do contexto familiar (HEMFELT; MINIRTH; MEIER, 1989 apud BRASIL, 2004). Um estudo correlacional desenvolvido por Gayol (2004) apresentou a associação entre codependência e alguns fatores de estresse, como perdas afetivas (morte, separação ou divórcio, abandono dos pais e/ou enfermidade crônica física ou mental de um familiar próximo durante os 12 primeiros anos da pessoa). Além disso, foram identificadas situações de violência doméstica na família de origem (abuso físico, sexual ou emocional), história de alcoolismo em familiares (avós, pais, irmãos), parceiro com problemas de alcoolismo, parceiro abusivo (violência física, sexual ou emocional) e condutas femininas submissas com o parceiro.

Quanto ao tratamento oferecido para o usuário de dependência química, desde os anos 50 tem se percebido a importância de oferecer um tratamento também à família, já que normalmente ela adoece junto com o dependente (ORTIZ, 2009; SECRETARIA DE SALUD, 1988 apud GAYOL; LIRA, 2002; SCHNEIDER et al., 2004). Nesse sentido, o tratamento da codependência pode ser vista por três vieses teóricos (FIGLIE, 2009). O primeiro viés é o modelo de doença familiar, que enfatiza o prejuízo funcional na família causado pelo uso e abuso da substância psicoativa. Essa substância afeta tanto o dependente quanto os membros da família. Autores envolvidos nessa abordagem apontam que crianças que se desenvolvem em um ambiente disfuncional apresentam maior probabilidade de terem o seu comportamento comprometido na fase adulta. Esse modelo visa a prestar atendimento para o(s) familiar(es) separado do dependente químico, semelhante aos grupos de autoajuda, para que possam entender os efeitos do consumo das substâncias e desenvolver maneiras saudáveis de lidar com o problema. O segundo viés, adotando o modelo comportamental, garante que os comportamentos são aprendidos e são mantidos por meio dos esquemas de reforçamento positivo e negativo dentro do próprio sistema familiar. Esse modelo permite observar padrões disfuncionais presente nas famílias, como por exemplo, na obtenção de atenção e cuidado com o reforçamento do beber, recebimento de amparo e proteção, quando o dependente relata experiências negativas causadas pelo hábito de beber, entre outros. $O$ tratamento visa à modificação do comportamento do membro envolvido a fim de servir como um reforçador para a abstinência do dependente. Utilizam-se técnicas para desenvolver estratégias de enfrentamento dos problemas, para facilitar a integração familiar e a comunicação entre seus membros. Já o último viés, o modelo sistêmico, considera a família como um sistema que se mantém num equilíbrio dinâmico. $\mathrm{O}$ uso da substância por um dos membros favorece para a homeostase da família. Nesse sentido, a codependência surge para compensar os problemas ocasionados pelo dependente químico. A partir das décadas de 70 e 80, profissionais da saúde que atuavam diretamente no tratamento a dependentes químicos sofreram influência desse modelo. Nas intervenções terapêuticas, utilizam-se técnicas que facilitam o entendimento do funcionamento familiar, além de promoverem mudanças de padrões e interações familiares. O presente trabalho utilizou como base teórica a abordagem sistêmica.

Visando à busca de critérios para constatar ou não a presença de codependência em mulheres de dependentes químicos, detacam-se os esforços de Gayol e Lira (2002). 
Além de estudar a codependência, as autoras construíram um instrumento que avalia a presença de codependência nestas mulheres, denominado Instrumento de Codependência (IOCD). No estudo de validação com mulheres mexicanas, a codependência foi vista como um problema de relação de dependência do casal, caracterizado por freqüentes estados de insatisfação e sofrimento pessoal, nos quais a mulher está envolvida em atender às necessidades de seu marido e de outras pessoas, sem considerar suas próprias vontades.

Na realidade brasileira, o estudo da codependência ainda se encontra incipiente, não sendo encontrados estudos ou instrumentos que acessem essa interação. Este trabalho, portanto, propôs-se a contribuir com o desenvolvimento desse campo, ao investigar as correlações entre a codependência e diversos aspectos da interação conjugal.

\section{MÉTODO}

\subsection{Delineamento}

Trata-se de uma pesquisa quantitativa correlacional. Investigou a presença ou não de codependência em mulheres de usuários de substâncias psicoativas ilícitas e correlações entre codependência, a idade das mulheres, o tipo de droga utilizando, o tempo de uso de substâncias ilícitas pelos maridos e o tempo dedicado para atender às necessidades dos parceiros.

\subsection{Amostra}

Participaram da pesquisa 30 mulheres de dependentes químicos. A idade média foi de 29, 43 anos ( $D P=7,07$ ). O método de escolha das participantes foi por conveniência, por todas apresentarem vínculo com uma mesma comunidade terapêutica do Vale do Paranhana. O critério de exclusão da amostra foi a presença de problemas neurológicos, o uso de álcool ou drogas e a identificação de dificuldades cognitivas. Quinze participantes eram mulheres de usuários que estavam em tratamento na comunidade terapêutica (denominados Alunos), quatro frequentavam o Café Convívio ${ }^{3}$, três mulheres cujos maridos haviam realizado tratamento antes de iniciarem o relacionamento com elas e oito mulheres cujos maridos fizeram tratamento na comunidade enquanto já estavam juntos. O tempo médio dedicado para atenção às necessidades do parceiro é de $11,73$ turnos por semana ( $D P=6,34)$. O tempo de convivência médio com esse parceiro é de 8,62 anos ( $D P=5,99)$. O tempo mínimo de convivência é de 11 meses e o máximo de 20 anos. $O$ grau de instrução, profissão e ocupação das participantes estão descritos na Tabela 1.

${ }^{3}$ Grupo de autoajuda que atende a familiares não vinculados à comunidade terapêutica. 


\begin{tabular}{llrr}
\hline Variáveis & \multicolumn{1}{c}{ Categorias } & F & \% \\
\hline \multirow{3}{*}{ Grau de Instrução } & Fundamental Incompleto & 7 & 23,3 \\
& Fundamental Completo & 5 & 16,7 \\
& Ensino Médio Incompleto & 3 & 10,0 \\
& Superior Incompleto & 2 & 6,7 \\
\hline \multirow{3}{*}{ Profissão } & Do lar & 6 & 20 \\
& Setor educacional & 4 & 13,3 \\
& Setor calçadista & 3 & 10 \\
& Serviços gerais & 17 & 56,7 \\
\hline \multirow{3}{*}{ Ocupação } & Atividades na igreja & 9 & 30 \\
& Do lar & 15 & 50 \\
& Atividades físicas & 2 & 6,7 \\
& Cursos & 4 & 13,3 \\
\hline
\end{tabular}

Tabela 1: Caracterização das participantes do estudo quanto ao grau de instrução, profissão e ocupação

Fonte: Dados da pesquisa.

\subsection{Instrumentos}

Ficha sociodemográfica - O questionário sociodemográfico foi especificamente elaborado para este estudo. Consiste em um questionário breve, estruturado para coleta de dados relativos à idade, escolaridade, profissão, ocupação, tempo de convivência com o usuário, tempo disponibilizado para atender às necessidades do esposo, tempo que o usuário esteve em tratamento, tempo que o usuário está em abstinência, tipo de substância utilizada e tempo de uso pelo marido.

Instrumento de Codependencia (ICOD) - O ICOD foi desenvolvido por Gayol e Lira (2002) e é composto de 30 afirmações. A escala pode ser autoaplicada ou ter sua utilidade em entrevista breve estruturada. É composta por uma escala do tipo Lickert de quatro pontos que variam de "não" (pontuada como 0) a "muito" (pontuada como 3), somando seu escore de 0 até 90 pontos. Estudos de consistência interna foram conduzidos (GAYOL; LIRA, 2002), encontrando um alpha de Crombach de 0,9201. Esse instrumento verifica a presença de codependência a partir de quatro dimensões conceituais propostas para definir a codependência: mecanismo de negação (fator 1 ), desenvolvimento incompleto da identidade (fator 2), repressão emocional (fator 3) e orientação resgatadora (fator 4). Gayol (2004) encontrou o escore de 32 pontos ou mais como ponto de corte para definir a presença de codependência na população mexicana.

O presente estudo utilizou a tradução para o português proposta pela autora, apesar de ainda não estar validada para a população brasileira. Manteve-se o ponto de corte validado à população mexicana. 


\subsection{Procedimentos para coletas de dados}

Após aprovação pelo Comitê de Ética em Pesquisa, foi realizado contato com a comunidade terapêutica onde os familiares dos Alunos que estão no programa de recuperação e reabilitação realizam visitas periódicas, visando a obter autorização para a realização da pesquisa com os familiares do sexo feminino nas dependências da instituição. Foi solicitada a assinatura do Termo de Concordância para a realização da pesquisa pela instituição. Com a aprovação da instituição, foram feitos contatos com as mulheres ao visitarem seus maridos. Além disso, foi feito contato com as mulheres participantes de grupos de autoajuda que a instituição realiza na comunidade. Visitas domiciliares também foram necessárias para a realização das entrevistas com as mulheres de homens que já não estavam mais na comunidade terapêutica. Foram explicados os objetivos de pesquisa, visando a salientar sua importância para o desenvolvimento da ciência e o compromisso com o sigilo e demais questões éticas de pesquisa com seres humanos. Cada participante leu e assinou um Termo de Consentimento Livre e Esclarecido, concordando em participar da pesquisa enfatizando-se o caráter voluntário da participação para as mulheres. Na entrevista, cada participante foi instruída sobre os instrumentos que foram utilizados. As participantes respondiam verbalmente as perguntas realizadas pela pesquisadora, enquanto acompanhavam a leitura dos instrumentos. Ao final da entrevista, era proporcionado um espaço para conversar sobre como tinha sido o processo de participação no estudo.

\subsection{Procedimentos para análise dos dados}

Os dados colhidos através dos instrumentos foram tratados e analisados através do pacote estatístico SPSS for Windows versão 16.0. Foram feitas análises correlacionais a fim de responder as hipóteses do estudo (comparação da identificação de codependência de acordo com a idade da mulher, o tempo de envolvimento com o usuário, o tipo de droga consumida e o tempo de uso da droga ilícita).

\section{RESULTADOS}

\subsection{Caracterização do uso de drogas dos parceiros}

O tempo dos parceiros no programa de recuperação foi em média de 6,5 meses $(D P=6,43)$, observando-se que 14 parceiros estavam em tratamento e 16 já haviam concluído o tratamento. Vinte e quatro parceiros estavam em abstinência e seis não estavam. Com relação ao uso de substâncias psicoativas, não houve diferença nos resultados referentes ao uso de álcool e maconha. Vinte e dois parceiros $(73,3 \%)$ faziam uso de álcool e maconha. Somente cinco parceiros $(16,7 \%)$ fizeram uso de loló. Vinte e um (70\%) parceiros fizeram uso de cocaína e crack. Somente dois parceiros $(6,7 \%)$ fizeram uso do pitico (maconha com crack).

\subsection{Análises sociodemográficas e do ICOD}

Após pormenorizados estudos da média, por item e total para a integralidade 
do grupo, realizou-se um estudo exploratório-descritivo dado por variável em questão (Tabela 2).

\begin{tabular}{lccccc}
\hline \multicolumn{1}{c}{ Variáveis } & Dimensões & \multicolumn{3}{c}{ Tendência central e dispersão } \\
\hline & Média & D.P. & Min & Max & Inter- quartil \\
ICOD & 46,233 & 1,446 & 2,00 & 68,00 & 15,50 \\
Tempo uso de drogas pelo parceiro & 9,300 & 5,730 & 2,00 & 25,00 & 5,75 \\
Tempo de dedicação ao parceiro & 11,73 & 6,341 & 2,00 & 21,00 & 14,00 \\
\hline
\end{tabular}

Tabela 2: Cálculos de tendência central e dispersão por variáveis em estudo Fonte: Dados da pesquisa.

A partir dos resultados apresentados na Tabela 2, podem-se destacar alguns aspectos interessantes. Quanto ao escore do ICOD, a média geral desta amostra foi de 46, 23 $(D P=1,44)$. Tendo em vista que a pontuação poderia variar de 0 a 90 , a média esperada poderia ser de 45 . 0 escore mínimo foi 2,00, denotando que algumas pessoas não indicam codependências, mesmo vivendo com um parceiro usuário de substâncias psicoativas.

Tendo como base o ponto de corte encontrado por Gayol e Lira (2002) com muIheres mexicanas, o presente estudo revelou que $90 \%(n=27)$ dessas mulheres poderiam ser consideradas codependentes. Esses dados, porém, não são plenamente confiáveis, tendo em vista que esse instrumento e ponto de corte não foi ainda validado na cultura brasileira. Mesmo assim, é possível pensar na existência de codependência, não somente pelos altos escores encontrados, mas também pela presença de outras variáveis com altos índices também auferidos, conforme descritas pormenorizadamente abaixo.

\subsection{Análise de correlações}

Foram conduzidas análises de correlação entre os níveis de codependência e a idade das mulheres. Entretanto, não foi encontrado nenhum resultado estatisticamente significativo $(\rho=0,197, p>0,05)$. Esses resultados parecem indicar que a idade das mulheres não afeta os índices de condependência. Também não foi encontrada uma correlação estatisticamente significativa entre o tempo de uso de substâncias ilícitas por parte dos parceiros destas mulheres e o escore de codependência $(\rho=0,285, p>0,05)$. A média do tempo de uso de drogas por esses parceiros foi de 9,30 anos ( $D P=5,73)$. Entretanto, foi possível observar a grande variabilidade de tempo de uso destas substâncias, por haver parceiros novatos com dois anos de uso, como parceiros chamados veteranos no uso de drogas, com até 25 anos de uso. Esses dados revelam a grande disparidade do uso de substâncias, além do aspecto da cronificação do problema em muitos casos, como daqueles que já estavam com 25 anos de uso. Esta não correlação com o tempo de uso de substâncias ilícitas dos parceiros pode estar ligada ao que a literatura estrangeira menciona sobre os sintomas de codependência estarem relacionadas a um sistema familiar disfuncional (BLACK, 1982 apud ORTIZ, 2009; SUBBY, 1987). Nesse caso, a codependência não está diretamente relacionada ao uso ou abuso de substâncias psicoativas, mas pode surgir em qualquer sistema familiar que mantém regras implícitas e explícitas interferindo no desenvolvimento emocional, psicológico, comportamental e espiritual da 
pessoa. Sendo assim, a codependência pode se relacionar a aspectos anteriores a essa união com um parceiro dependentes de substâncias psicoativas (pai alcoolista, abuso, violência intrafamiliar, por exemplo). Outra correlação investigada que não demonstrou relevância estatística foi entre o escore de codependência e o tempo de dedicação das participantes aos seus parceiros $(\rho=0,094, p>0,05)$. Apesar da média do tempo de dedicação estar em 11,73 turnos por semana de dedicação ( $D P=6,341)$, é possível ressaltar a presença acentuada de mulheres que dedicam todos os turnos da semana às necessidades do marido (26,67\%). Esses dados revelam uma alta dedicação para tentar controlar o uso do parceiro, na expectativa de sua abstinência às drogas. Essa atitude está de acordo com o que a literatura fala sobre codependência (ZAMPIERI, 2004).

Uma correlação estatisticamente significativa refere-se ao tempo de dedicação da esposa ao cuidado com o marido/companheiro e o tempo de abstinência. Essa correlação indicou que quanto maior o tempo de abstinência, menor o tempo de envolvimento da esposa com o parceiro $(\rho=-0,369 ; p<0,05)$. Esse dado pode fortalecer uma visão sistêmica do funcionamento familiar. Quanto mais o usuário de drogas se mantém afastado do uso, menor é a necessidade de uma atitude de cuidado constante por parte de esposa (FIGLIE, 2009).

Após a busca por correlações, foram realizadas algumas análises de variâncias entre grupos (Teste T). Os grupos foram definidos em função da presença ou não de indicativo de codependência. Através dessa análise, observou-se diferença estatisticamente significativa com relação ao parceiro ter feito ou não tratamento $(F=5,436 ; p<0,05)$. $O$ grupo das mulheres cujo marido/companheiro já fez tratamento apresenta um índice maior de codependência do que o grupo das mulheres cujos maridos/companheiros nunca passaram ou fizeram tratamentos. Os dados coletados com as mulheres não explicam esses resultados. Entretanto podem-se pensar alguns aspectos teóricos que influenciam na construção e conscientização do quadro de copedendência. Entre eles, destacam-se: a busca por tratamento já exige um envolvimento familiar mais acentuado do que quando o uso não é entendido como dependência; quando o tratamento envolve, mesmo indiretamente, os familiares, pode-se abrir um espaço de visibilização de quanto a dependência estava controlando o funcionamento familiar; essa visibilização pode gerar uma postura de mudança de atitude nas mulheres, tornando-as mais críticas quanto às atitudes que antes reforçavam o uso das substâncias. Se essas hipóteses são verdadeiras, o tratamento auxilia tanto o usuário quanto as parceiras no entendimento das dependências. Esses dados reafirmam os achados da literatura que, desde a década de 50, já vem dando importância aos aspectos emocionais e comportamentais dos familiares do usuário (ORTIZ, 2009; SILVA, 2009; ABLON, 1974 apud ORTIZ, 2009).

A pouca significância nas correlações investigadas pode ser resultado do elevado número de casos de codependência identificados ao utilizar-se o ponto de corte proposto por Gayol (2004). Observando 90\% da amostra foram consideradas codependentes, não é possível identificar outras diferenças entre os comportamentos destas com o restante das esposas. Uma análise mais criteriosa do instrumento e a verificação do ponto de corte possivelmente permitirão o esclarecimento da não presença de resultados estatisticamente significativos. 


\subsection{Aspectos subjetivos das entrevistas}

Além dos dados estatísticos desta pesquisa, cabe ressaltar alguns aspectos das entrevistas com essas mulheres. A alta dedicação aos seus parceiros ficou bastante clara no momento das entrevistas, quando algumas mulheres chegaram a relatar: "Eu parei com tudo: faculdade, cursos, minha família, para ajudar ele, não falei pra ninguém. [...]. Já faz um ano que ele está abstinente, porém não sei se aguentaria passar por tudo que eu passei de novo, caso ele recaísse". Além disso, outras mulheres comentaram que preferiram manter em segredo o seu sofrimento. Esse comportamento é comum nas pessoas codependentes, pois preferem ferir a si mesmas do que aos outros, além de não verbalizarem os problemas pessoais e interpessoais (WOITITZ; WEGSCHEIDER; WHITFILD, 1984 apud ISQUIERDO, 2001).

A maioria das mulheres expressou que sentiam medo de revelar seu sofrimento, devido ao preconceito e à reação das pessoas. Contudo, percebe-se a necessidade de ter à sua disposição um espaço para escuta. Algumas mulheres comentaram que, após a entrevista, estavam se sentindo melhor. Uma mulher chegou a comentar: "Como é bom poder falar um pouco da gente, estou me sentindo melhor". Outra mulher falou "Tinha dúvidas sobre como eu deveria proceder com ele. [...]. Sempre tive vontade de perguntar para um profissional, se a maneira que eu estava agindo com ele era a correta".

Cabe ainda ressaltar que, durante a experiência de coleta de dados, percebeu-se uma dificuldade de encontrar dependentes químicos que ainda recebiam alguma atenção de companheiras ou esposas. A maioria das pessoas que assistem às necessidades dos usuários de substâncias psicoativas são membros da família de origem - nesse caso, a mãe, irmã, entre outros. Durante a seleção de esposas disponíveis para participar do estudo, foi possível acompanhar algumas mães comentando: "mãe é mãe, eu não vou abandonar meu filho. Precisamos ter paciência e acreditar que ele vai conseguir [ficar abstinente]. O pai dele já mandou ele embora de casa, mas eu não deixei. Como eu vou fazer isso com o meu filho!!!". Essa realidade indica a necessidade de se desenvolver instrumentos que identifiquem e mensurem a codependência em cuidadores e/ou familiares de origem (não somente de esposas), devidamente adaptados à realidade brasileira.

\section{CONSIDERAÇÕES FINAIS}

Os dados desta pesquisa podem auxiliar aos profissionais que trabalham diretamente com famílias com comportamentos disfuncionais. Por meio desse material, poderá melhorar-se o entendimento da codependência nas famílias brasileiras, bem como desenvolver estratégias que possam auxiliar no tratamento do dependente químico e da sua família. Apesar de o instrumento utilizado não estar adaptado à realidade brasileira, o acentuado número de mulheres identificadas como codependentes é um dado relevante, denotando a presença dessa disfunção no contexto familiar do dependente de substâncias psicoativas ilícitas.

De acordo com o instrumento, $90 \%$ das mulheres entrevistadas apresentaram índices de codependência (utilizando como referência a validação para a população mexicana). A idade da mulher, o tempo que ela dedica para atender às necessidades do parceiro, o tipo de droga consumida por ele e o tempo de uso da substância não 
apresentaram correlações estatisticamente significativas com relação aos índices de codependência apresentados. São necessários maiores esforços para aprofundar o conhecimento nessa área e desenvolver instrumentos que mensurem o índice de codependência nas famílias brasileiras, especialmente ampliando a investigação para outras cuidadoras (inserindo as famílias de origem).

A verificação da codependência em mulheres de usuários de substâncias ilícitas pode ser considerada um fato novo nessa área de estudo, tendo em vista a inexistência de pesquisas brasileiras que mencionem a utilização deste instrumento (ou de qualquer outro) para avaliar se há ou não índices de codependência nessa população. Nesse sentido, será importante a continuidade dos estudos na área.

\section{REFERÊNCIAS}

ALL ABOUT COUNSELING. Overview of codependency. 1998. Disponível em: <http://www.allaboutcounseling.com/codependency.htm>. Acesso em: 27 maio 2009.

ANDRADE, Arthur Guerra de. A importância do conhecimento científico no combate ao uso nocivo de tabaco, álcool e drogas ilícitas. Revista de Psiquiatria Clínica, São Paulo, v. 35, supl. 1, 2008.

BEATTIE, Melody. Codependent no more. Hazelden. 1992. Disponível em: <http://books.google.com.br/books?id=JX-leLk-9TOC\&pg=PP1\&dq=Codependent+ no+more\#PPA4,M1>. Acesso em: 7 maio 2009.

BRASIL, Valéria Rocha. Família e drogadição. In: CERVENY, Ceneide Maria de Oliveira (Org.). Família e... Comunicação, Divórcio, Mudança, Resiliência, Deficiência, Lei, Bioética, Doença, Religião e Drogadição. São Paulo: Casa do Psicólogo, 2004.

CABRAL, Gabriela. Drogas Ilícitas. Disponível em: <http://www.brasilescola.com/ drogas/drogas-ilicitas.htm>. Acesso: 7 maio 2009.

DIMENSTEIN, Magda; ZAMORA, Maria Helena; VILHENA, Junia de. Da vida dos jovens nas favelas cariocas. Drogas, violência e confinamento. Revista do Departamento de Psicologia/UFF, 2004. Disponível em: <http://www.uff.br/ichf/publicacoes/ revista-psi-artigos/2004-1-Cap2.pdf>. Acesso em: 13 maio 2009.

FERREIRA, Daniela Roland. Alcoolismo e codependência: a interferência do alcoolismo na dissolução da relação conjugal. 2008. 57 f. Trabalho de Conclusão de Curso (Psicologia), Universidade do Sul de Santa Catarina, Palhoça, 2008.

FERRUZZI, Fernanda Trombeta et al. Redução da idade penal: uma questão em debate. 2004. 69 f. Monografia (Serviço Social), Faculdades Integradas Antônio Eufrásio de Toledo, Presidente Prudente, 2004.

FIGLIE, Neliana Buzi. O tratamento da dependência química na família. Disponível em: <http://www.adroga.casadia.org/codependencia/co-dependencia_tratamento_ amilia_dependencia.htm>. Acesso em: 28 maio 2009.

GAFAS. Codependência. Disponível em: <http://www.gafas.org.br/co-dependente.tml>. Acesso: 27 maio 2009.

GAYOL, Gloria Noriega. Codependencia: un guión de vida transgeneracional.

Transactional Analysis Journal, v. 34, n. 4, out. 2004. 
GAYOL, Gloria Noriega; LIRA, Luciana Ramos. Construcción y validación del instrumento de Codependencia (ICOD) para las mujeres mexicanas. Salud Mental, México, v. 25, n. 2, abr. 2002.

HINTZ, Helena Centeno. Novos tempos, novas famílias? Da modernidade à pós-modernidade. Pensando Famílias, Porto Alegre, n. 3, 2001.

IBGE. INSTITUTO BRASILEIRO DE GEOGRAFIA E ESTATÍSTICA. Drogas Ilícitas. Disponível em: <http://www.fiocruz.br/biosseguranca/Bis/infantil/drogas_ilicitas.html>. Acesso em: 7 maio 2009.

ISQUIERDO, Fernando Mansilla. Codependencia y psicoterapia interpersonal. Rev. Asoc. Esp. Neuropsiq., Madri, v. XXXI, n. 80, 2001.

LÔBO, Paulo Luiz Netto. A repersonalização das relações de família. 2004. Disponível em: <http://jus2.uol.com.br/doutrina/texto.asp?id=5201\&p=1>. Acesso em: 11 maio 2009.

NARDI, Antônio Egidio. Distúrbios de Ansiedade. Disponível em: <http://emedix.uol. com.br/doe/psi003_1f_ansiedade.php\#6>. Acesso em: 12 jun. 2009.

ORTIZ, Daniel Rocha. Codependencia: una revisión histórica del término I. Disponível em: <http://www.liberaddictus.org/Pdf/0313-24.pdf>. Acesso em: 20 maio 2009.

PILLON, Sandra Cristina; O’BRIEN, Beverley; CHAVEZ, Ketty Aracely Piedra. The relationship between drugs use and risk behaviors in brazilian university students. Revista Latino-Americana de Enfermagem, Ribeirão Preto, v. 13, n. 2, dez. 2005.

SCHNEIDER, Daniela Ribeiro et al. Caracterização dos serviços de atenção à dependência química da região da grande Florianópolis. 2004. Disponível em:

<http://www.psiclin.ufsc.br/Relat\%F3rio\%20Caracteriza\%E7\%E3o\%20dos\%20 Servi\%E7os.pdf>. Acesso em: 1 jun. 2009.

SILVA, Eroy Aparecida da. Codependência e mulheres: uma questão de gênero? Disponível em: <http://www.anjt.org.br/index.php?id=99\&n=127>. Acesso em: 20 maio 2009.

SILVA, Ilma Ribeiro. Alcoolismo e abuso de substâncias psicoativas: tratamento, prevenção, educação. São Paulo: Vetor, 2000.

SOARES, Ana Cláudia; REZENDE, Constança. Seminário do MP discute combate ao tráfico de drogas. 2007. Disponível em: <http://www.jusbrasil.com.br/noticias/ 160456/ seminario-do-mp-discute-combate-ao-trafico-de-drogas>. Acesso em: 12 maio 2009.

SORJ, Bila; FONTES, Adriana; MACHADO, Danielle Carusi. Políticas e práticas de conciliação entre família e trabalho no Brasil. Cadernos de Pesquisa, v. 37, n. 132, 2007.

SUBBY, Robert. Lost in the shuffle. Flórida: Health Communications, Inc. 1987.

VAITSMAN, Jeni. Flexíveis e plurais: identidade, casamento e família em circunstâncias pós-modernas. Rio de Janeiro: Rocca, 1994.

VASCONCELLOS, Rodrigo Silva; PERGHER, Giovanni Kuckartz. Estudo correlacional entre alexitimia e dependência química. 2008. 17 f. Trabalho de Conclusão de Curso (Psicologia), Faculdades Integradas de Taquara, Taquara, 2008.

VIEIRA, Denise Leite et al. Álcool e adolescentes: estudo para implementar políticas municipais. Revista de Saúde Pública, São Paulo, v. 41, n. 3, 2007.

ZAMPIERI, Maria Aparecida Junqueira. Co-dependência: o transtorno e a intervenção de rede. São Paulo: Agora, 2004. 